\title{
Imprudência humana tragicamente poética
}

\author{
Vera Bastazin ${ }^{1}$ \\ http://lattes.cnpq.br/4107059968334160 \\ http://orcid.org/0000-0002-5584-9197
}

Antonio Coutinho Soares Filho ${ }^{2}$

http://lattes.cnpq.br/1066054198529341

Enviado em: 19/08/2019

Aceito em: 07/09/2019

\begin{abstract}
RESUMO: Entre a tessitura de referências à cultura oriental e a poética da linguagem, Valter Hugo Mãe coloca nas mãos de seus leitores o romance Homens imprudentemente poéticos, que propõe não apenas a continuidade de seus escritos, mas um convite para o mergulho nas estranhas do ser, traçando uma perspectiva não apenas episódica, mas sobretudo imagética. Neste sentido, o artigo aqui apresentado refaz, de certa forma, uma caminhada pela narrativa contemporânea, evidenciando uma intersecção de teor existencial, místico e mito-poético. A magia da linguagem instiga e fascina o leitor, seja pela construção das relações de intersubjetividade que se estendem do núcleo familiar para o social, seja pela ambientação espectral que atinge momentos de tensão e lirismo. $\mathrm{O}$ enfoque mito-trágico é outro aspecto do romance que, ao revelar sentimentos primitivos do homem, evidencia um quadro de animosidade e inquietações interiores dos protagonistas. A análise proposta se estende para o ideário grego, retomando componentes ou condições do trágico que oferecem uma possibilidade enriquecedora de leitura da obra em movimentos constantes entre a miséria do cotidiano e a consciência iluminadora que alimenta o fazer artístico como forma de intermediação entre os homens.
\end{abstract}

Palavras-chave: Trágico. Mito e Literatura. Valter Hugo Mãe. Homens imprudentemente poéticos.

ABSTRACT: Between the thesis of references to Eastern culture and the poetics of language, Valter Hugo Mãe puts in the hands of his readers the novel Homens imprudentemente poéticos, which proposes not only the continuity of his writings, but also an invitation to immerse oneself in the entrails of the individual, outlining an episodic and, above all, imagery, perspective. Therefore, the present article, in a way, retraces a journey through contemporary narrative, highlighting an intersection of existential content, mystical and mythical-poetic. The magic of language incites and fascinates the reader; by building the relationships of intersubjectivity that extend from the family unit to the social, or by the spectral atmosphere that reaches periods of tension and lyricism. The mythotragic approach is another aspect of the novel, which, by revealing man's primitive feelings, emphasizes a picture of animosity and inner restlessness of the protagonists. The analysis extends to the Greek ideology, taking up components or conditions of the tragic that offer an enriching possibility of reading the book in constant movements between the misery of everyday life and the enlightening conscience that feeds the artistic practice as a way of intermediation among the men. Keywords: Tragic. Myth and Literature. Valter Hugo Mãe. Homens imprudentemente poéticos.

\footnotetext{
${ }^{1}$ Doutorado em Comunicação e Semiótica pela Pontifícia Universidade Católica de São Paulo, Brasil (1994). Professora Associada da Pontifícia Universidade Católica de São Paulo, Brasil. E-mail: vbastazin@uol.com.br

${ }^{2}$ Professor de Teoria Literária (Universidade Estadual da Região Tocantina do Maranhão - UEMASUL) e Técnico em Assuntos Educacionais - TAE (Instituto Federal de Educação, Ciência e Tecnologia do Maranhão - IFMA/Campus Imperatriz). Mestrado em Literatura e Crítica Literária (PUC-SP). E-mail: coutinhofilho70@gmail.com
} 


\section{Introdução}

A força das ideias era tanta que pensar se tornava também uma disciplina do fogo. Pensar era um modo de arder. (MÃE, 2016, p. 169).

\section{Poética de múltiplos caminhos}

Valter Hugo Mãe é um escritor com ânsia de amplitude. Depois de percorrer os recantos portugueses nos primeiros romances e os fiordes islandeses em $A$ desumanização (2014), ele aporta no Japão arcaico com Homens imprudentemente poéticos (2016). Com esse novo salto espaçotemporal, o romancista, numa prosa lírica e encantatória, inscreve a trajetória do artesão Itaro e do oleiro Saburo. As personagens são moradores de uma anônima aldeia de Quioto no sopé do monte Fuji e à entrada da Floresta Aokigahara, conhecida como mar de árvores, mas referida na obra apenas pelo seu epíteto popular de floresta dos suicidas.

Vaticinado por um mal irremediável, Itaro divide-se entre a preocupação com o futuro de sua irmã, Matsu, a menina cega, e o fabrico de leques no intuito de garantir o próprio sustento enquanto o presságio de uma cegueira não se efetiva. Paralelo a isso, o artesão vive num estado crescente de rivalidade com o vizinho Saburo, um homem marcado pela morte trágica de sua esposa, a senhora Fuyu. Sem razões aparentes, esses homens alimentam um ódio recíproco, o qual se mostra num latente desejo assassino. "Por seu lado, Saburo, sentimental, pensava que, se pudesse, gostaria de matar o artesão. Depois, ponderava e pensava que gostaria de o ver morto.” (MÃE, 2016, p. 60). De igual modo, "Itaro, se pudesse, gostaria de o ver morto. Depois, pensava, se pudesse, gostaria de o matar.” (MÃE, 2016, p. 60).

Esse quadro de animosidade, associado às inquietações interiores dos protagonistas, é o fio condutor a partir do qual Hugo Mãe tece uma narrativa com forte teor existencial, místico e mito-poético. A tessitura do romance constrói uma atmosfera lírica, contribuindo para isso a brevidade dos capítulos, as frases curtas, a oclusão de minúcias narrativas, bem como, na esteira saramaguiana, a mescla de narração e discursos das personagens no interior dos parágrafos. Pode-se mesmo dizer que o texto de Mãe cria a imagem linguística do modo de vida daquela esquecida aldeia de Quioto, um ambiente carregado de silêncio, de reclusão, de interdição, de um cotidiano monótono, mas, interiormente, intenso.

Nesse contexto, o cenário do Japão arcaico, sobremodo o isolamento do vilarejo, é um dos elementos fundamentais para que venham à tona os sentimentos mais primitivos do homem. Contudo, é importante ressaltar que as escolhas espaciais de Hugo Mãe não são meros exercícios literários de exploração de paisagens exóticas. Se em $A$ desumaniz̧ação, os fiordes, dentre outras possibilidades interpretativas, metaforizam a desolação e o desamparo do ser humano, em Homens imprudentemente poéticos, o espaço é propício a uma ambientação espectral e mítica, na qual sacralidade e humanidade atingem pontos altos de tensão e lirismo.

[...] Uns cem passos de jardim sob as copas das primeiras árvores, um larido de cores e perfumes que contrastava com o rude que as coisas selvagens podiam ser. [...] O jardim na floresta era uma renda colorida na franja subindo da montanha. No pé da montanha, junto ao caminho abria a planície, onde imediato se punham as casas e se lavravam os campos. [...] Para Matsu as montanhas podiam fazer promontórios que se suspendessem sobre as aldeias. Braços de pedra que se levantavam entre as nuvens e sombreavam as aldeias. (MÃE, 2016, p. 30)

Mais que o procedimento episódico, prevalece, no romance, o imagético. Nesse universo, 
destacam-se os leques de Itaro, a floresta dos suicidas, o poço no qual Itaro enfrenta a fera real-imaginária, o sábio enigmático, o quimono da senhora Fuyu e, ainda, o jardim de Saburo. De igual modo, a vidência de Itaro, a presença de feras invisíveis e as constantes referências aos mortos e aos deuses compõem um conjunto ficcional no qual o mítico, a fantasmagoria e o místico não passam despercebidos.

Em razão disso, a presente análise adota a perspectiva mito-trágica, tendo como ponto de partida o jardim de Saburo, visto, aqui, como local de desmedida e de purgação humana. Considerando essa linha interpretativa, o esforço do oleiro em cultivar as flores é uma afronta aos deuses, pois seu intento é evitar a realização do presságio que ameaça a vida de sua esposa e o fim de sua felicidade. Em outros termos, Saburo é um mortal em confronto direto com a força implacável do destino. Esse princípio trágico é, assim, uma das chaves de leitura da obra, uma espécie de fio de Ariadne, não para fugir, mas para percorrer o intrincado labirinto mito-poético de Hugo Mãe.

\section{A Moira no jardim}

O jardim de Saburo nasce envolto numa atmosfera mito-trágica, visto que o oleiro inicia a obra como forma de driblar o terrível destino anunciado pelo artesão: "Por três vezes o vizinho Itaro the dissera que um animal esfaimado haveria de baixar a montanha para lhe matar a mulher." (MÃE, 2016, p. 30). Diante do presságio, "Saburo, justificado pelo amor, magoou-se longamente e quis saber de que modo poderia demover tal fera de lhe trazer tão impossível dor. O vizinho, talvez por pouca definição das suas premonições, talvez incauto, o aconselhou a mudar a natureza." (MÃE, 2016, p. 30). Rejeitando o que lhe dita o futuro, Saburo leva a sério a recomendação irônica do artesão, pois este, na verdade, ao recomendar a mudança da natureza, "Queria certamente aludir à utopia de [Saburo] o conseguir [...]" (MÃE, 2016, p. 30), dado que o destino já reservara ao casal aquela triste sina.

Em relação a essa presença premonitória, pode-se dizer que Itaro personifica a força imperiosa da Moira, quer dizer, o destino. Segundo o ideário grego antigo, o homem, ao nascer, recebe seu daímon, "uma divindade intermediária entre homens e deuses, e o homem, apesar de ter o daimon como transcendente, mantém com ele laços mais próximos que com os deuses." (GAZOLLA, 2001, p. 64). Dito de outro modo, essa divindade particulariza cada ser humano, por isso ela "diz respeito a seu destino singular, explicita o lote que a Moira consigna a cada um quando do nascimento." (GAZOLLA, 2001, p. 64).

Sob esse aspecto, a tragédia grega configura-se como a encenação de uma vida fadada ao fracasso em virtude de uma imprudência do herói trágico ou de fatos anteriores a seu nascimento, como é o caso de Édipo, o lendário rei de Tebas. Para melhor compreender a dimensão dessa arte dramática é preciso levar em conta o contexto político, social, mítico e religioso no qual ela floresceu. Assim, para a leitura da tragicidade no romance de Hugo Mãe, interessa saber que o percurso trágico envolve três elementos, a saber, býbris, hamartía e Moira, os quais expressam a cosmovisão helênica da Antiguidade. Ressalte-se que a tragédia ficou datada no tempo, mas o trágico não se limita ao gênero dramático, podendo então ser encontrado numa narrativa fílmica ou num romance.

A par desses “componentes ou condições do trágico” (MAFRA, 2010, p. 73), é possível empreender uma leitura desse aspecto no texto literário fora do âmbito estrito da tragédia grega. Desse modo, a hamartía é uma falha trágica que, consciente ou não, acompanha o homem assinalado pela tragicidade. Nas palavras de Mafra, "A leitura e a reflexão, aos poucos, levam a descobrir que a hamartía pode estar no herói ou em situação anterior que envolve a sua vida." 
(2010, p. 74), a exemplo de Édipo, "marcado por um destino trágico não por força de uma falha sua, mas por força de acontecimentos anteriores ao seu nascimento." (2010, p. 74). A falha trágica não se dá por um desvio de caráter do herói, mas por circunstâncias que fogem a seu controle, como antigas manchas ou crimes familiares, ou por ele desrespeitar sua limitação humana, considerado pelos deuses como uma afronta grave a seu poderio. De qualquer forma, a Moira trama a sorte dos que serão agraciados ou desgraçados.

Por seu turno, a býbris significa a desmedida humana, uma impetuosidade que, residente no coração do homem, o leva a não aceitar seus limites, chamado pelos gregos de métron. $\mathrm{O}$ herói trágico tem o peito inflamado pelo arroubo de ultrapassar sua condição mortal, ele anseia se igualar aos deuses, comportamento altamente condenável pelos olímpicos numes. A býbris, "Do ponto de vista da tragédia, é a falta ou o pecado daquele que é excessivo, orgulhoso, insolente etc., qualidades pelas quais um homem entra em conflito com outro homem ou com os deuses, ou com outras forças superiores." (MAFRA, 2010, p. 76). Assim, a býbris constitui o sentimento exacerbado do homem frente a suas limitações, a qual é o fio condutor da hamartía, a falha trágica.

Com isso, percebe-se que o conceito de trágico, na cultura grega, está atrelado ao sentido de ordem e controle. Desse modo, "o anér, o ator, o herói torna-se êmulo dos deuses." (BRANDÃO, 2009, p. 11), ou seja, é lançado sobre o herói trágico a cegueira da razão (áte) para que todas as suas iniciativas se revertam contra ele. Note-se que a busca de Édipo desemboca em sua derrocada, sua palavra real o condena ao exílio e sua capacidade intelectual o conduz à terrível verdade de suas origens. Nublado pela áte, o anér vai ao encontro do aniquilamento, seu espírito exacerbado faz com que se fechem sobre ele "as garras da Moĩ $\alpha$, 'Moira', o destino cego.” (BRANDÃO, 2009, p. 11). Para a plateia grega, o castigo do herói era modelar, a punição se devia a sua ousadia - ou a de seus ancestrais - em desafiar os ditames das divindades enciumadas, o que, no plano político, representava uma forma de interdição aos que se atrevessem desafiar a estabilidade da pólis. Nesse sentido, garante Gazolla que

Sem afastar a crença no lote que Moira distribui a cada homem, no nascimento, e que vem a constituir o ser que lhe é próprio, o homem da pólis reconsidera seus valores e ações por meio do herói, tendo sob os olhos o que de mais terrível e tocante poderá acontecer-lhe se resolver assumir a desmesura (2001, p. 80).

Portanto, a representação da tragédia conciliava a um só tempo o espetáculo artístico, o ritual mítico-religioso, a memória identitária do povo grego e a propaganda ideológica a serviço do controle dos cidadãos frente ao poder estatal. A apresentação teatral congregava, sob a égide do mito, a ideologia da prevalência da pólis sobre os anseios do sujeito, em outros termos, o comunitário acima do individual, este visto como o princípio da fatalidade, aquele como o caminho da felicidade.

\section{Oleiro das flores}

Do ponto de vista do trágico, os esforços de Saburo concernentes ao cultivo do jardim são inúteis. Sua luta inglória, porém, faz dele um homem imprudentemente poético, pois ele acreditava que "se destituísse a floresta do seu cariz selvagem amansariam as bestas, ganhariam coração, seriam um pouco domésticas, como alguns pássaros que se habituavam a amizades com as gentes." (MÃE, 2016, p. 30-31). A imprudência de Saburo o leva a sonhar com um mundo apaziguado no qual o selvagem e o humano sejam capazes de se irmanar. Inicialmente, o oleiro, 
ingênuo, acredita ser possível, por meio de seu jardim, escapar do quinhão ruim que a Moira lhe reservara.

Saburo alegrava-se julgando que o esforço sensibilizaria também o espírito divino. O tempo passava e a sorte continuava. Era um sinal de que o destino se compadecia com o plano bonito de mudar absurdamente as maneiras do mundo. Dizia: ando a curar o destino. Acreditava que o mérito convencia os deuses, como se os pudesse também educar. (MÃE, 2016, p. 31).

Contudo, o anúncio profético da Moira-Itaro se realiza. Com a morte da senhora Fuyu, Saburo se dá conta de sua impotência diante do destino: "O oleiro falhara. Agraciado três vezes com a adivinha de Itaro, nem assim se melhorara ao ponto de salvar a esposa.” (MÃE, 2016, p. 34). Desse modo, o relato da morte da mulher adquire contornos sobrenaturais, conforme atesta o esposo aos moradores do vilarejo: " $\mathrm{E}$ as pessoas lhe diziam o que ele mesmo lhes contara, que o animal assomara ao interior da casa como fumo. Era um espírito, uma assombração. Mordera a senhora Fuyu com o mando do destino." (MÃE, 2016, p. 34). Tal como Édipo, depois de comprovada sua insensatez, o oleiro reconhece que o fato "Era decisão do espírito divino, havia que ser respeitada. A senhora Fuyu teria a celebração que lhe competia, Saburo deveria apaziguar-se com os deuses. Era uma decisão. O oleiro tinha de a aceitar. Era claramente uma decisão.” (MÃE, 2016, p. 34).

Esse ponto do percurso trágico de Saburo coincide com o que Aristóteles (2014) chama, em sua Poética, de patético. De fato, ensina o sábio estagirita que o enredo do drama trágico compõe-se de três partes, quais sejam, a peripécia, o reconhecimento e o patético. A primeira "é uma reviravolta das ações" (ARISTÓTELES, 2014, p. 30), enquanto o segundo são as revelações em cena as quais levam ao desenlace funesto. O patético, por sua vez, "consiste numa ação que produz destruição ou sofrimento, como mortes em cena, dores cruciantes, ferimentos e ocorrências desse gênero.” (ARISTÓTELES, 2014, p. 31).

Nesse cenário, o patético, pathos, é o movimento dramático cuja função é provocar na assistência terror e piedade, conforme preconiza Aristóteles: "É a tragédia a representação duma ação grave [...], a qual, inspirando pena e temor, opera a catarse própria dessas emoções" (2014, p. 24, grifos nossos). Como consequência do reconhecimento, o herói trágico é tomado pelo pathos. Essa explosão de emoções antecede a catarse, a qual, por sua vez, traz o aniquilamento do anér. Dessa forma, a comunidade aprende que a ordem estabelecida não deve ser abalada. Lembrese que a tragédia, em última instância, é uma pedagogia social.

Seguindo o roteiro convencional, esse seria o clímax do drama trágico quando a Moira, efetivando seu desígnio, leva o herói à purgação (catarse) de sua býbris. Édipo vaza os olhos como autopunição, Antígona se enforca, Clitemnestra é assassinada pelo filho, Othelo se apunhala após a consciência do erro a que fora induzido. Fugindo ao receituário trágico, Saburo mostra que a paixão pela esposa é uma desmedida que nem mesmo o destino pode aplacar. Assim, passado o choque, contradizendo-se, ele cria uma forma de presentificar aquela que se fora, dando mostras de seu inconformismo com os ditames divinos. O coração desmedido do oleiro não aceita a morte da esposa, ele recusa a solidão.

Assim, "Uns dias mais tarde, ainda incapaz de se dirigir às flores, o oleiro pendurou o quimono da mulher no espantalho do seu quintal. Espaventava ali a imitar-lhe a companhia. Dizia: imita ver os pássaros.” (MÃE, 2016, p. 34). Desse modo, a senhora Fuyu, numa representação fantasmagórica, volta a habitar a casa, o jardim e a vida do oleiro, bem como toda a aldeia: "A terra do oleiro parecia observada para sempre pela mulher. Era uma mulher abundante. Restava.” (MÃE, 2016, p. 35). Contrariando a função estrita do espantalho de afastar os pássaros das plantações, o quimono da senhora Fuyu é signo de sua permanência. Sob a ação 
do vento, a vestimenta agita-se como se a dona da roupa tivesse renascido. Simbolicamente, o oleiro repete a cena genesíaca quando o Criador dá vida à criatura humana: "Então Iahweh Deus modelou o homem com a argila do solo, insuflou em suas narinas um hálito de vida e o homem se tornou um ser vivente." (Gn 2,7) ${ }^{3}$. Em vez do barro, o oleiro usa o tecido; no lugar do respiro divino, o vento que agita seu jardim.

Sob a perspectiva mítica, Saburo tenta transpor sua condição humana, ambicionando, mesmo que inconscientemente, a posição da divindade. Nesse sentido, seu jardim metaforiza o Éden com o qual ele tenta afastar a fera que, conforme a profecia de Itaro, ronda sua mulher. $\mathrm{Na}$ visão cristã, a fera que espreita todos os homens é o pecado, princípio do mal no mundo e motivo de expulsão do Paraíso. Neste ponto, considerando o forte teor simbólico do romance, aventura-se uma hipótese, qual seja, a de que a senhora Fuyu pode ter sido assassinada pelo marido, tendo como motivo o amor quase obsessivo que o mesmo demonstra dedicar a sua companheira. Não se pode conjecturar uma infidelidade, a obra não fornece maiores informações, contudo a premonição de Itaro em relação ao perigo que rondava a vizinha poderia ser atribuída à fera do desejo interior que habita todo homem e toda mulher.

O oleiro voltou às flores. Dizia: são uma escola. Ensinarão lentamente até os bichos mais casmurros e antigos, os que já só pertencem ao lado da morte. Queria dizer, os de fumo. Aqueles que talvez chegassem sem descer a floresta. Aqueles que se consumavam por dentro do destino de cada um, certamente admitidos ou convidados pela incúria moral ou pela ignorância. Bichos que vinham do próprio sangue." (MÃE, 2016, p. 35, grifo nosso).

Lembre-se que os vaticínios, na esteira do oráculo de Delfos, não são discursos objetivos, mas simbólicos, tanto que a Pítia - sacerdotisa suprema de Delfos - fazia suas predições em estado de transe, necessitando, muitas vezes, que sua mensagem fosse interpretada. Nessa ótica, a narrativa fantástica da morte da senhora Fuyu poderia ser vista como a forma encontrada por Saburo, aproveitando-se do discurso premonitório de Itaro, de acobertar seu crime e, ao mesmo tempo, de purgar sua culpa.

De qualquer forma, a trajetória de Saburo se encaminha pelo trágico, visto que sua býbris o impulsiona não só a desafiar os deuses, mas a eles tentar se igualar. O oleiro, ao contrário do anér trágico, não desiste de seu intento após a morte da mulher, tanto que ele "voltou às flores e mesmo às noites. Quando levava as preces e o incenso, acordado indefinidamente pelo desnível da encosta, luzindo apenas um pouco na solidão." (MÃE, 2016, p. 35). Se, antes, o jardim era forma de afastar o mau presságio, agora, ele é prática catártica, seja movido pelo desejo de agradar os deuses para trazê-la de volta ou, caso se admita o assassínio da esposa, sua autopunição: "Saburo pensava que, se o jardim fosse maior, seria imperdível até aos olhos dos deuses. E os deuses o amariam e, se o amassem, lhe devolveriam a senhora Fuyu ou, ao menos, a fariam feliz até que ele se lhe juntasse." (MÃE, 2016, p. 35).

Os esforços do oleiro são em vão, sua perseverança não resulta no renascimento da esposa. Desse modo, Hugo Mãe encena, com a trajetória dessa personagem, a esperança catártica de um desejo que não se efetiva. No entanto, nem tudo é estéril, pelo contrário, os esforços de Saburo fazem dele um herói. Se os deuses condenam os excessos do coração humano, o narrador do romance inscreve a atitude desse protagonista na esfera épica: "Nunca se ouvira de um amor que ressuscitasse. Mas as melhores lendas contavam de heróis que nunca desistiam. Saburo era assim. Recusava desistir.” (MÃE, 2016, p. 35). Assim, se a obstinação pode ser trágica,

${ }^{3}$ Livro do Gênesis.

https://periodicos.unifap.br/index.php/letras

Macapá, v. 9, n. 1, $1^{0}$ sem., 2019 
não deixa também de ser heroica, quer dizer, o ser humano torna-se grande porque, mesmo ameaçado por suas limitações, é capaz de empreender as tarefas mais árduas, inclusive, as improváveis. O que constitui nossa humanidade é o buscar, não necessariamente o conseguir.

\title{
Imprudência e poesia
}

O caráter de Saburo e sua forma de enfrentar a vida incomodam profundamente Itaro, gerando neste um antagonismo não muito justificável em relação ao vizinho. A paixão do oleiro por sua mulher, a tentativa de driblar a vontade dos deuses e aplacar a selvageria das feras ao plantar o jardim são atitudes que intrigam o artesão. Em vista disso, ele interpreta negativamente a persistência do rival em manter as flores como forma de seduzir os deuses para que lhe devolvam a esposa ou a preservem em paz no mundo dos mortos até que o casal volte a se reencontrar no plano espiritual. A forma como Saburo concebe seu ofício é outro fator que agrava a animosidade entre os protagonistas. $\mathrm{Na}$ visão de Itaro, o outro distorce a natureza do amor, como também o trabalho de olaria. Por isso,

\begin{abstract}
O artesão pensava no vizinho oleiro como um incauto sentimental. Por paixões várias, agia igual a uma criança imbecil. Até os pratos e as taças que cozia enfeitava absurdamente, a infligir à pureza do barro a utopia ridícula de ser uma fantasia. Aceitava mal que o barro fosse só o que era. Aliás, nunca aceitaria a natureza de quase nada. Implicava-se com as coisas do mundo e queria ser uma autoridade para os aspectos e para os significados do que o rodeava. Por isso, Itaro o rejeitava. Era fraco. Suspirava pelos mortos sem os honrar porque perdia a robustez. Era mais velho pela covardia e pela opção por ser um sonhador do que pela idade. (MÃE, 2016, p. 60).
\end{abstract}

Essa aversão de Itaro pelo vizinho coaduna-se com a postura da irascível Moira em relação aos desafetos mortais. Em decorrência disso, o artesão persegue Saburo, chegando a ponto de roupar o quimono da senhora Fuyu, forma simbólica de castigar o adversário. Em meio à tempestade, Itaro se lança a recolher o vestuário, pois "queria o quimono perdido da senhora Fuyu a todo o preço. Haveria de o sequestrar em absoluto segredo para se abeirar dele matador, como quem atormentava um prisioneiro. Apreciaria o desalento do vizinho.” (MÃE, 2016, p. 92). Assim, o artesão se delicia com o sofrimento de Saburo, o qual, ao se dar conta do sumiço da vestimenta, "carpia no chão, entre o restolho das flores, esse morto lugar da sua esperança." (MÃE, 2016, p. 93).

O roubo do quimono fora antecedido da destruição das flores do jardim: “O artesão, rasteiro de braços e também com os pés, matou todas as flores no exacto momento em que a primavera ia começar" (MÃE, 2016, p. 86). Momentos antes, o artesão surpreendera o vizinho dormindo embriagado vestido no quimono da esposa: "Era ele por dentro da pele vazia da mulher. Os dois misturados momentaneamente" (MÃE, 2016, p. 85). Diante dessa visão, Itaro, enquanto personificação do daímon ruim de Saburo, deseja vingar-se daquele que ousa sonhar apesar dos maus augúrios e da perda efetiva da mulher. Nesse sentido, Itaro não compreende a imprudência poética do oleiro no esmero de sua arte, no fato dele ressuscitar imageticamente a esposa na peça de vestuário e, ainda mais, em continuar a embelezar a selvageria da floresta dos suicidas.

A solidão de Saburo não é destrutiva, pelo contrário, do nada, do caos, das derrotas, ele consegue criar, pois sabe que "A criação é uma necessidade existencial. É produto e produtora da própria espécie. Ela está no homem como condição de vida.” (BASTAZIN, 2006, p. 28-29). Itaro não tem essa percepção de vida apesar de, também, ser um artista. No entanto, como homem utilitário ameaçado pelo presságio de uma cegueira iminente, ele dedica-se à produção 
dos leques como forma de prover o sustento de Matsu e da senhora Kame.

Neste ponto, é preciso salientar que a mola do destino tem seus revezes. Se, por um lado, Itaro metaforiza a Moira de Saburo, por outro, ele também é um joguete de forças que o ultrapassam. Predestinado a uma cegueira que se aproxima a cada dia, ele passa a ser atormentado pelo fantasma do pai e pela fera invisível que o ataca na floresta. Apesar de conseguir resolver a situação da irmã cega, arranjandolhe um pretendente às escondidas do vilarejo, o artesão não consegue livrar-se de seus demônios interiores. Na esteira de Hamlet, Itaro é perseguido pela sombra do pai, não para pedir vingança, mas para vingar-se do filho: "Quando o corpo lhe chegou junto, o rosto exposto à reveladora luz, Itaro mais se amedrontou e disse: peço perdão, senhor meu pai. Peço perdão, senhor meu pai. E o pai o tocou em mão de ferro para o esganar" (MÃE, 2016, p. 109). Diante disso, notase que a relação de Itaro com o pai é muito mais edipiana do que hamletiana, sendo o espectro do genitor a personificação do daímon terrível que ameaça o artesão. Este entende que o pai morto o pune pelo abandono de Matsu, por sua irreverência com os mortos, pelos males provocados a Saburo, como também pelas mortes dos animais usados para adivinhação. Dá-se, em termos aristotélicos, o reconhecimento trágico do protagonista, o qual, consciente de sua býbris, anseia por uma purificação.

Nesse contexto, o emblemático episódio do poço inicia o processo catártico de Itaro, no qual ele enfrenta sua fera interior. Com essa experiência, ele aprende a conviver com a selvageria que o habita, resultando no resgate de sua alma estiolada, metaforizada no invisível animal ferido. Depois desse evento, Itaro pode continuar sua purgação interna, visto que ele fora iluminado pela coragem de assumir a própria solidão e a sua capacidade criativa.

\section{O leque e o barro}

Seguindo a trilha do processo trágico, vê-se que o último lance de Homens imprudentemente poéticos ocorre com a manifestação do pathos dos protagonistas. A quarta parte do romance, intitulada $A$ sindrome de Itaro, encena o clímax da rivalidade e do apaziguamento dos dois artesãos. Enquanto Itaro se apossa de sua arte, Saburo dá vazão a uma fúria assassina até então latente. Assim, é notável a caçada que o oleiro empreende ao vizinho, a qual só não termina em catástrofe devido à interferência da senhora Kame usando o quimono fantasmático da esposa de Saburo como bandeira de paz:

Entre o interminável canavial, o oleiro e o artesão se caçavam em fúria. E, súbito, aquela senhora Fuyu apareceu elevada observando o intenso ódio com os seus preciosos olhos espirituais. Itaro hesitou. Saburo deitou-se por terra à vergonha do amor. O sabre imediatamente vazio de morte. Apenas vergonha. (MÃE, 2016, p. 165).

Depois desse episódio, Itaro e Saburo, tomados pelo patético, põem em prática atos desmedidos a fim de executarem a catarse. O oleiro, envergonhado pelo desejo homicida, decide apagar, definitivamente, a memória da esposa. Em vez das peças de barro, Saburo incinera, sob os olhares perplexos da vila, o quimono espectral: "Atendiam à cerimônia fúnebre. Imediatamente olharam o espantalho vazio e sentiram que a senhora se fora embora novamente. Mais do que nunca. A senhora Fuyu morrera por completo." (MÃE, 2016, p. 169). Diante do acontecimento, o povo conclui que "O oleiro curava-se, a mulher libertava-se." (MÃE, 2016, p. 170). Além disso, Saburo abandona de vez o plantio do jardim. Agora, ele é um deus vencido, na verdade, apenas um mortal perante a realidade, pois fora expulso do mundo da fantasia. $\mathrm{O}$ simulacro da esposa e o jardim impossível perdem seus efeitos mágicos, restando ao oleiro 
apenas aceitar sua humanidade.

Por seu turno, Itaro experiencia a descoberta da potencialidade da arte. De homem prático, cotidiano, que considerava que "A utilidade era a única ciência decente" (MÃE, 2016, p. 63), torna-se, de fato, alguém com uma alma de artista. Antes, a produção dos leques tinha como finalidade imediata suprir a carência financeira, evitar a arte da fome; depois, ela ganha contornos sobrenaturais, o que leva o artesão a recusar-se a vendê-los por mais que insistam:

Pago três vezes, dizia um homem. Pago quatro vezes. À escuta dos valores, Itaro gemia como se o preço fosse uma arma contra aquela paixão. Negava sempre. E mais o homem repetia: seis vezes. E mais Itaro se contorcia atingido pela avidez, resistindo contra a tentação de também enriquecer. (MÃE, 2016, p. 160).

Dessa forma, Itaro intui a sacralidade da existência a partir do contato com o divino da criação artística. Pode-se mesmo dizer que o artesão deixa-se levar pela desmedida da invenção. Destarte, ele tornar-se um anér, inaugurando seu próprio processo trágico, não mais como Moira de Saburo, mas como um homem de býbris. A arte é seu excesso, sua tentativa de palmilhar o território da divindade:

A arte, por seu lado, mais do que a presciência tinha o sublime. Podia servir apenas para ser pura transcendência. Quando Itaro descia sobre as suas pinturas e as protegia estava a recolher com o corpo o inteiro mundo dos espíritos. Dizia: para a alegria de cada deus. Sentia-se o criador de uma prova dos deuses. (MÃE, 2016, p. 159).

À vista disso, Itaro atinge um estado de clarividência tão assombrosa que a visão humana torna-se insuportável, ele chegara a vislumbrar o mistério divino: "O artesão obstinava-se e considerava o resto dos seus olhos e as suas mãos como autorizações divinas, oficiais dos deuses que abriam na realidade uma urgente graça." (MÃE, 2016, p. 157). Nesse ponto, o artesão assemelha-se ao homem que conseguira penetrar a luz da verdade conforme indica Platão na alegoria da caverna em sua República. Ao mesmo tempo em que lança luz, a luminosidade excessiva pode cegar, em outros termos, a arte traz luz, mas também perturba, é desconfortante.

Nesse quadro de consciência e perturbação, depois de visualizar o rosto de Matsu no leque há muito guardado, Itaro entende ter chegado à perfeição artística. Assim, ao mesmo tempo em que ele não deseja abrir mão da transcendência, também tem consciência do poder terrífico que a arte possui, por isso sente que "Nunca mais suportaria a angústia de criar." (MÃE, 2016, p. 175). Por conseguinte, é preciso pagar o preço para permanecer no plano artístico-divinal. A catarse, nesse caso, resulta na automutilação: "Tomou a sua lâmina e sorriu. Lembrou-se, olhar para sempre. [...]. Ser como um elemento de universalidade. Saber apenas das ideias, a essência de cada coisa. Ficar livre. Itaro pensou, ficar livre. Furou os olhos.” (MÃE, 2016, p. 175).

$\mathrm{O}$ ato desmedido de Itaro o qualifica aos olhos alheios como um homem insensato, no entanto, ele encontra, na cegueira, a iluminação de si, do mundo e da arte. Ao contrário de Édipo, a atitude de Itaro resulta no encontro da plenitude. Como o adivinho Tirésias, ele sabe mais das coisas do que quando enxergava. Nesse ponto, Saburo se aproxima do vizinho como um igual. Depois de todas as perdas, os homens se apaziguam. Como o oleiro, Itaro torna-se, também, um homem imprudentemente poético, capaz de enxergar a luz na escuridão, a esperança no caos, a companhia na solidão. Finalmente, ele entende Saburo, sente o outro como um igual. Irmanam-se.

Assim, o romance de Hugo Mãe, apesar de ter um percurso trágico, não segue à risca o receituário grego. Pelo contrário, operam-se mudanças interessantes. Em vez do catastrófico, 
Itaro e Saburo compreendem e aceitam as dores e aleluias da realidade humana. A Moira, também, se rende à desmedida e a catarse não é castigo, mas plenitude. Nesse quadro, os protagonistas conseguem suportar as perdas, seja a visão ou o paradeiro de Matsu, seja o fim do jardim ou a morte definitiva da mulher amada. Ao mesmo tempo, percebe-se uma inversão de polos, a saber, Itaro passa de pragmático a contemplador do etéreo ao passo que Saburo abandona o imagético para se fixar no cotidiano. Por isso mesmo, eles se entendem, conhecem os dois lados da moeda, mais que isso, já tiveram suas efígies cravadas em ambas as faces da vida.

Sem o jardim, o oleiro só tem o barro para moldar o ganha pão. Sem a iluminação dos olhos, ao artesão resta, por mais estranho que seja aos outros, a alegria da mendicância. Desse modo, Itaro e Saburo experimentam a miséria cotidiana, mas conscientes de que a vida humana é algo além do que se mostra. Destarte, o romance de Hugo Mãe expõe as mazelas dos excluídos socialmente, incluídos nesse rol os artistas populares. Contudo, o escritor português faz isso com a veia poética que lhe é peculiar como a dizer que a arte salva o homem de sua profunda miséria, mesmo que esta seja inexplicável em termos humanistas. O narrador chama o leitor a ampliar seu horizonte de visão. O barro não é somente argila, é a matéria divina da qual Deus fez o ser humano. O leque não é apenas bambu, é a força que movimenta o ar, o sopro divino.

\section{REFERÊNCIAS}

ARISTÓTELES. Arte poética. In: ARISTÓTELES, HORÁCIO, LONGINO. A poética clássica: arte poética (Aristóteles), arte poética (Horácio), Do sublime (Longin). Trad. Jaime Bruna. Introd. Roberto de Oliveira Brandão. 17 reimpres. São Paulo: Cultrix, 2014.

BASTAZIN, Vera. Mito e poética na literatura contemporânea: um estudo sobre José Saramago. São Paulo: Ateliê, 2006.

BRANDÃO, Junito de Souza. Teatro grego: tragédia e comédia. 11. ed. Petrópolis: Vozes, 2009. GAZOLLA, Rachel. Para não ler ingenuamente uma tragédia grega: ensaio sobre aspectos do trágico. São Paulo: Edições Loyola, 2001. (Coleção Leituras Filosóficas).

GÊNESIS. In: Bíblia de Jerusalém. Nova edição, revista e ampliada. São Paulo: Paulus, 2002.

MÃE, Valter Hugo. A desumanização. 2. reimpressão. São Paulo: Cosac Naify, 2014.

. Homens imprudentemente poéticos. Prefácio de Laurentino Gomes. São Paulo: Biblioteca Azul, 2016.

MAFRA, Johnny José. Cultura clássica grega e latina: temas fundadores da literatura ocidental. Prefácio de Audemaro Taranto Goulart. Belo Horizonte: PUC-Minas, 2010. 